\title{
Sonographic evaluation of congenital cystic neck masses with histopathological correlation
}

\author{
Gazi Salahuddin', Md Tarikul Islam², Md Mahmudul Huq ${ }^{3}$, Sutanu Kumar Mondal', Md Abdus \\ Sobhan $^{5}$, Dhrubo Kumar Mondal ${ }^{6}$
}

\begin{abstract}
Background: Accurate diagnosis is important for planning of management of the congenital cystic neck mass. Clinical history, physical examination and appropriate knowledge of embryology and anatomy of the cervical region frequently allow the differential diagnosis to be narrowed and ultrasound especially high frequency ultrasound help to further confirmation. USG has been used as the initial imaging procedure in the evaluation of them. Ultrasound not only confirms the cystic nature of the lesion but also evaluates exact location, size, extent, relation to the surrounding structures and internal characteristic of mass.
\end{abstract}

Objectives: To establish the usefulness of ultrasound in the evaluation of congenital cystic neck masses.

Methods: From January 2014 to March 2018 a total 50 patients with clinically suspected congenital cystic mass in the neck region were selected who under want operative treatment and histopathological examination. A through history taking and physical examination were done then patient were scanned with gray scale ultrasound and colour Doppler in necessary case. Histopathological report collected from the patient and compare with USG diagnosis.

Results: In USG 37 patient diagnosed as congenital lesions and 13 patient diagnosed as non-congenital lesion. Among the congenital lesions thyroglossal duct cyst-19, branchial cleft cyst-12, cystic hygroma-4, hemangioma-1 and epidermoid cyst-1. In histopathology 32 patient diagnosed as congenital lesion and 18 diagnosed as non-congenital lesion. Among the congenital lesions thyroglossal duct cyst-18, branchial cleft cyst-8, cystic hygroma-4, hemangioma-1 and epidermoid cyst-1. Among the 19 USG diagnosed thyroglossal duct cyst 17 is confirmed by histopathology and 2 is differ. Among the 12 USG diagnosed branchial cleft cyst 7 is confirmed by histopathology and 5 is differ. Over all sensitivity of USG-93.7\% and specificity- $64 \%$ and accuracy- $74 \%$.

Conclusion: USG is a useful modality for the diagnosis of congenital cystic mass in the cervical region.

Keywords: Congenital, Sonography, Histopathology, Thyroglossal duct cyst, Branchial cleft cyst and Cystic hygroma.

1. Assistant professor, Dept. of radiology, Khulna Medical College.

2. Assistant professor, Dept. of burn and plastic surgery, Khulna Medical College.

3. Assistant professor, Dept. of ENT, Khulna Medical College.

4. Associate professor, Dept. of ENT, Khulna Medical College.

5. Medical officer, Shahid Sheikh Abu Naser Specialized Hospital, Khulna.

6. Medical officer, Shahid Sheikh Abu Naser Specialized Hospital, Khulna. 
Address of correspondence: Dr Gazi Salahuddin. Assistant professor, Dept. of radiology, Khulna Medical College. Mob-01711162654.Email: drgsuddin73@gmail.com

\section{Introduction}

Congenital cystic masses in the cervical region are a relatively frequent findings, usually diagnosed in infancy and childhood but detection may be delayed until adulthood. They often manifest as slow growing masses and causes symptoms only after enlarging sufficiently or after infection. ${ }^{1}$

Common lesions are thyroglossal duct cyst, branchial cleft cyst, cystic hygroma, hemangioma, dermoid and epidermoid cyst. The clinical history and physical examination and appropriate knowledge of embryology and anatomy of the cervical region frequently allow the differential diagnosis to be narrowed and ultrasound especially high frequency ultrasound help to further confirmation. Ultrasound not only confirms the cystic nature of the lesion but also evaluates exact location, size, extent and internal characteristic of mass and act as a guide for FNAC. ${ }^{1}$

During the 4th gestational week, the thyroid primordial grows caudally from the foramen cecum, through the prepharyngeal soft tissues along a midline descent, the anterior neck, anterior and in close proximity to the developing hyoid bone, to its eventual destination in the inferior neck. ${ }^{2}$ As the developing gland travels caudally, an epithelial tract is left behind that develops into the thyroglossal duct. ${ }^{3}$ The duct generally involutes

by the $5^{\text {th }}$ to $10^{\text {th }}$ week of gestation, leaving only a proximal remnant at the foramen cecum, and a distal portion that differentiates into the pyramidal lobe of the thyroid gland. ${ }^{2}$ Persistence of any portion of the duct can lead to the formation of cysts or ectopic thyroid rests along the tract.

Thyroglossal duct cysts represent $70 \%$ of all congenital neck masses and are the most common congenital cervical abnormality after Thornwaldt cysts. ${ }^{4}$ About $50 \%$ of patients present before 20 years of age with a second group of patients presenting in young adulthood. ${ }^{5,6}$ Usually manifests as an enlarging, painless mass in the anterior midline of the neck. They characteristically move upward with tongue protrusion, a reflection of the origin of the duct at the foramen cecum. ${ }^{7}$ They have variable sonographic appearance such as anechoic $28 \%$, homogenously hypoechoic with internal debris $18 \%$, pseudosolid $28 \%$, and heterogeneous $28 \%$. The majority showed posterior enhancement $88 \%$, were midline $63 \%$ and infrahyoid in location $83 \%$. Only half of all thyroglossal duct cysts showed a typical thin wall. ${ }^{8}$

Branchial cleft cysts are the most common non-inflammatory pediatric lateral neck masses; almost all arise from the second branchial cleft. ${ }^{1}$ Which represent $95 \%$ of bronchial cleft anomalies with cyst being more common than fistulae and sinus. ${ }^{9}$ These lesions are thought to arise from incomplete obliteration of the embryologic cervical sinus of His. Second branchial cleft cysts are most commonly found at the angle of the mandible along the anteromedial border of the sternocleidomastoid muscle, but can occur anywhere from the oropharyngeal tonsillar fossa to the supraclavicular neck. ${ }^{10}$

These cysts usually appear as painless, fluctuant masses in the lateral portion of the neck adjacent to the anteromedial border of the sternocleidomastoid muscle at the mandibular angle. ${ }^{11}$ Sonographically they are sharply marginated, round to ovoid, centrally anechoic mass with a thin peripheral wall and shows distinct acoustic enhancement.

Lymphangiomas of the head and neck most commonly occur in the posterior cervical triangle followed by the axilla and the tongue 
musculature. ${ }^{12}$ Lymphangiomas are thought to develop from sequestration of a portion of the embryologic lymphatics (most commonly involving the jugular lymph sac), resulting in continued growth and accumulation of fluid. ${ }^{13}$

Cystic hygroma is the most common form of lymphangioma. Majority (about $80 \%$ $90 \%$ ) are detected by the time the patient is 2 years old. ${ }^{14,15}$ Most cystic hygromas manifests as a multilocular predominantly cystic mass with septa of variable thickness. The echogenic portions of the lesions correlate with clusters of small, abnormal lymphatic channels. ${ }^{16}$

\section{Dermoids and epidermoids are the second-most common midline cervical anomalies after thyroglossal duct cysts. ${ }^{17}$ The most common clinical appearance of a dermoid cyst in the neck is a midline, suprahyoid, and slowly growing mass. ${ }^{18}$ Unlike thyroglossal duct cysts, they have no intimate association with the hyoid bone and therefore do not move with tongue protrusion. ${ }^{19}$ All the cysts have internal echoes, with a solid appearance with only slight or no posterior echo enhancement. ${ }^{20}$ Epidermoid cysts are rare lesion; they have same sonographic appearance as dermoid cyst.}

Ultrasound, CT and MRI are the imaging modalities for evaluation of cystic neck masses. It is already mansion ultrasound not only confirms the cystic nature of the lesion but also evaluates exact location, size, extent, relation to the surrounding structures and internal characteristic of mass and act as a guide for FNAC. CT and MRI also provides this information and is ideally suited for evaluation of soft tissue planes adjacent to larger masses that cannot be entirely visualized with US. But CT and MRI is costly, CT has radiation hazard and MRI time consuming On the other hand ultrasound is easy, low cost, radiation free, readily available and repeatedly useable for follow up scans of the patient.

The main objectives of this study was to establish the usefulness of ultrasound in the evaluation of congenital cystic neck masses.

\section{Materials and methods}

This cross sectional study was carried out on randomly selected 50 patients with clinically suspected congenital cystic mass in the neck region attended the department of Radiology \& Imaging of Khulna medical college hospital and Vital research diagnostic centre, Khulna from January 2014 to March 2018 for performing ultrasound and later on underwent operative treatment and histopathology examination. History taking and physical examination were done first then ultrasongram were done by high resolution gray-scale ultrasonography by using $7.5 \mathrm{MHz}$ liner array probe and help of $3.5 \mathrm{MHz}$ probe were taken in the relevant cases. Color flow study also done to identify vascular malformation. The following outcome variables were studied- age, sex, time of presentation in relation of birth, site, USG feature such as echogenicity, loculation, wall thickness, far wall echo enhancement and internal debri of the lesion. Finding of histopathological examination were collected from the patient. Data were collected in a pre-designed structured data collection sheets. All the relevant collected data were compiled on a master chart. The result USG diagnosis is compare with histopathological diagnosis and finally discrepancy between them is shown. Further statistical analysis of the result was done by using computer software (SPSS).

\section{Results}

From January 2014 to March 2018 total 50 consecutive cases with clinically suspected congenital cystic neck masses were studied. $48 \%$ of the patients were in $2^{\text {nd }}$ decade, followed by $38 \%$ in $1^{\text {st }}$ decade $\& 12 \%$ in $3^{\text {rd }}$ and above decade group. The mean age of the patient was $14.2 \pm 1.33$ years. (Table-I)

Out of 32 histopathologically confirmed congenital cystic lesion 19(59.37\%) were located medial position and $13(40.62 \%)$ were lateral position of the neck. (Table- II) All thyroglossal duct cysts are anterior midline mass with close association with hyoid bone, Branchial cleft cysts are lateral neck mass. In 
USG both are anchoic or hypoechoic with or without debri and sepation with posterior echo enhancement of all the lesion. (Fig-I \& Fig-II) Cystic hygroma are multilocular predominantly cystic mass with septa of variable thickness. (Fig-III) Epidermoid cyst showing moderately thin walled, unilocular cystic lesion having coarse internal echoes without posterior echo enhancement. (Fig-IV)

In USG 37 diagnosed as congenital lesions and 13 as non-congenital lesions. Among the congenital lesions thyroglossal duct cyst-19 (51.4\%), branchial cleft cyst-12 (32.4\%), cystic hygroma-4 (10.8\%), hemangioma-1 (2.7\%) and epidermoid-1 (2.7\%). (Table-III \& V)

In histopathologically 32 diagnosed as congenital lesions and 18 as non-congenital lesions. Among the congenital lesions thyroglossal duct cyst-18 (56.3\%), branchial cleft cyst-8 (25\%), cystic hygroma-4 (12.5\%), hemangioma-1 (3.1\%) and epidermoid-1 (3.1\%). (Table-IV \& V)

Among the 19 USG diagnosed thyroglossal duct cyst 17 is confirmed by cytology and 2 is differ. Among the 12 USG diagnosed branchial cleft cyst 7 is confirmed by cytology and 5 is differ. Accuracy of USG for thyroglossal duct cyst-89.4\%, branchial cleft cysts- $58.33 \%$, cystic hygroma, hemangioma and epidermoid cyst-100\% for each. (Table-VI) Over all sensitivity of USG $-93.7 \%$, specificity- $64 \%$ and accuracy-74\%.

Table-I: Distribution of the patients by their age-group.

\begin{tabular}{|l|c|c|c|}
\hline $\begin{array}{l}\text { Age Group } \\
\text { ( in years) }\end{array}$ & $\begin{array}{c}\text { Number of } \\
\text { patients }\end{array}$ & $\begin{array}{c}\text { Percentage of } \\
\text { patients }\end{array}$ & $\begin{array}{c}\text { Mean age } \\
\pm \text { SE in year }\end{array}$ \\
\hline$\leq 10$ & 19 & 38 & \multirow{2}{*}{$14.2 \pm 1.33 \mathrm{yr}$} \\
\hline $11-20$ & 24 & 48 & \\
\hline $21-30$ & 06 & 12 & \\
\hline $31-40$ & 01 & $\mathbf{1 0 0}$ & \\
\hline Total & $\mathbf{5 0}$ & 02 & \\
\hline
\end{tabular}


Table-II: Types of neck masses with their location.

\begin{tabular}{|l|c|c|c|}
\hline \multirow{2}{*}{$\begin{array}{l}\text { Histopathological } \\
\text { types }\end{array}$} & \multicolumn{2}{|c|}{ Location of neck mass } & Total \\
\cline { 2 - 4 } & 19 & Lateral & \\
\hline Congenital masses & $(59.37 \%)$ & $(40.62 \%)$ & \\
\hline $\begin{array}{l}\text { Non-congenital } \\
\text { masses }\end{array}$ & 6 & 12 & 18 \\
\hline Total & $(33.33 \%)$ & $(66.66 \%)$ & 50 \\
& 25 & 25 & \\
\hline
\end{tabular}

Table-III: Distribution of individual lesion on the basis of USG diagnosis.

\begin{tabular}{|c|c|c|c|}
\hline \multicolumn{2}{|l|}{ Congenital lesions } & \multicolumn{2}{|l|}{ Non-congenital lesions } \\
\hline Types of lesion & Number patient & Types of lesion & Number patient \\
\hline Thyroglossal duct cyst & 19 & Cold abscess & 05 \\
\hline Branchial cleft cyst & 12 & Thyroid cyst & 03 \\
\hline Cystic hygroma & 04 & Thyroid carcinoma & 01 \\
\hline Hemangioma & 01 & Lymphadenopathy & 04 \\
\hline Epidermoid cyst & 01 & & \\
\hline Total & 37 & Total & 13 \\
\hline
\end{tabular}


Table-IV: Distribution of individual lesion lesions on the basis of hitopathological diagnosis.

\begin{tabular}{|c|c|c|c|}
\hline \multicolumn{2}{|l|}{ Congenital lesions } & \multicolumn{2}{|l|}{ Non-congenital lesions } \\
\hline Types of lesion & Number patient & Types of lesion & Number patient \\
\hline Thyroglossal duct cyst & 18 & Cold abscess & 07 \\
\hline Branchial cleft cyst & 08 & Thyroid cyst & 05 \\
\hline Cystic hygroma & 04 & Thyroid carcinoma & 01 \\
\hline Hemangioma & 01 & Lymphadenopathy & 05 \\
\hline Epidermoid cyst & 01 & & \\
\hline Total & 32 & Total & 18 \\
\hline
\end{tabular}

Table-V: Comparative chart of USG and histopathological diagnosis of congenital cystic mass.

\begin{tabular}{|l|c|c|}
\hline Congenital mass & USG diagnosis & Histopathological diagnosis \\
\hline Thyroglossal duct cyst & $19(51.4 \%)$ & $18(56.3 \%)$ \\
\hline Branchial cleft cyst & $12(32.4 \%)$ & $08(25 \%)$ \\
\hline Cystic hygroma & $04(10.8 \%)$ & $04(12.5 \%)$ \\
\hline Hemangioma & $01(2.7 \%)$ & $01(3.1 \%)$ \\
\hline Epidermoid cyst & $01(2.7 \%)$ & $01(3.1 \%)$ \\
\hline Total & $\mathbf{3 7 ( 1 0 0 \% )}$ & $\mathbf{3 2 ( 1 0 0 \% )}$ \\
\hline
\end{tabular}


Table-VI: Comparative chart \& discrepancy between USG and histopathological diagnosis with accuracy of USG diagnosis.

\begin{tabular}{|c|c|c|c|c|}
\hline \multirow[t]{2}{*}{ USG diagnosis } & \multirow{2}{*}{$\begin{array}{l}\text { Number of } \\
\text { patient }\end{array}$} & \multicolumn{2}{|c|}{ Histopathological diagnosis } & \multirow{2}{*}{$\begin{array}{c}\text { Accuracy of USG } \\
\text { diagnosis }\end{array}$} \\
\hline & & $\begin{array}{l}\text { Number of } \\
\text { case } \\
\text { confirm }\end{array}$ & Number of case differed & \\
\hline Thyroglossal cysts & 19 & 17 & 2 (Thyroid cyst ) & 89.4 \\
\hline Branchial cleft cysts & 12 & 7 & $\begin{array}{c}3 \text { (Cold abscess) } \\
2 \text { (lymphadenopathy) }\end{array}$ & 58.33 \\
\hline Cystic hygroma & 4 & 4 & & 100 \\
\hline Hemangioma & 1 & 1 & & 100 \\
\hline Epidermoid cyst & 1 & 1 & & 100 \\
\hline Cold abscess & 5 & 4 & 1 (Thyroglossal cysts) & 80 \\
\hline Thyroid cyst & 3 & 3 & & 100 \\
\hline Thyroid carcinoma & 1 & 1 & & 100 \\
\hline Lymphadenopathy & 4 & 3 & 1 (Branchial cleft cyst) & 75 \\
\hline Over all & 50 & 41 & 9 & 82 \\
\hline
\end{tabular}

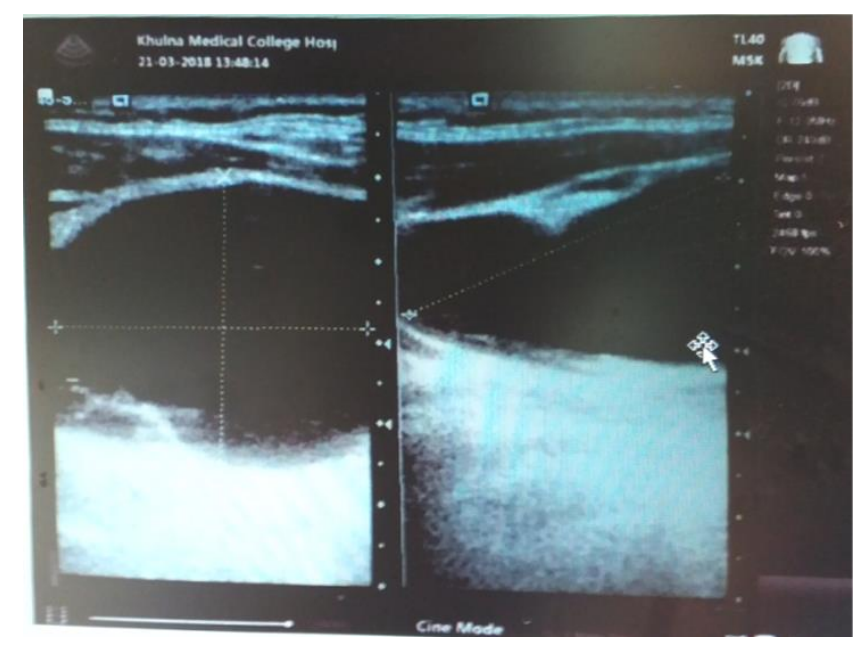

Fig I: Thyroglossal duct cyst: A midline infrahyoid neck mass showing anechoic thin walled, unilocular cystic lesion with posterior echo enhancement. 


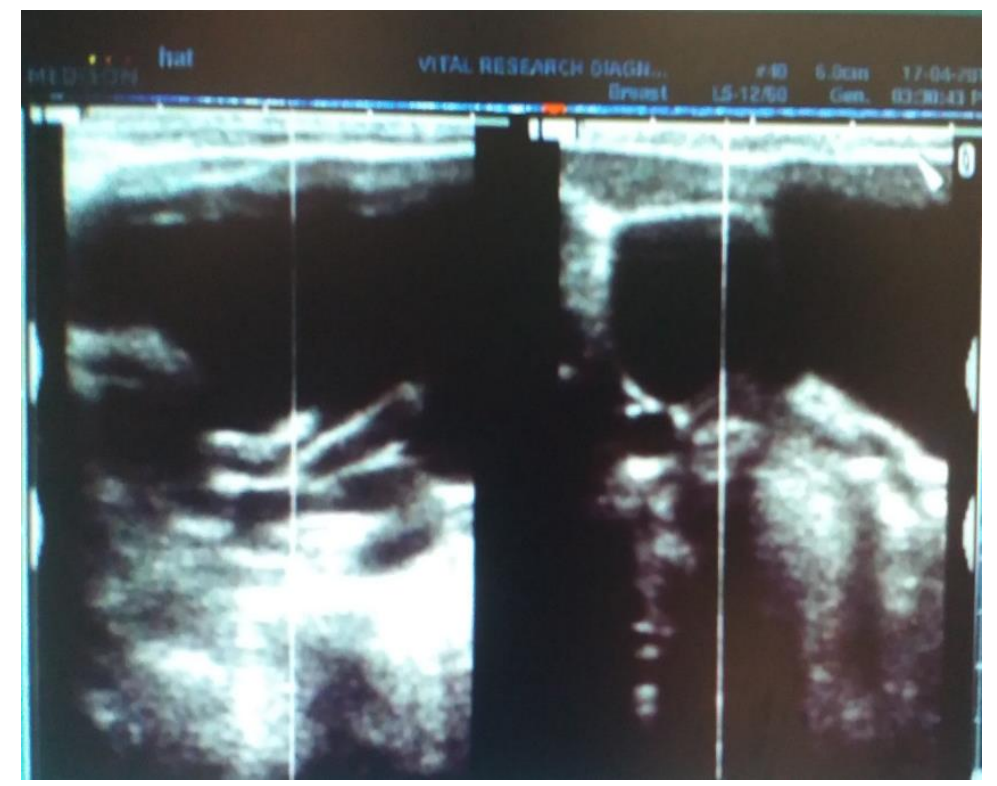

Fig II: Branchial cleft cyst: A lateral neck mass showing anechoic, thin walled septet cystic lesion with posterior echo enhancement.

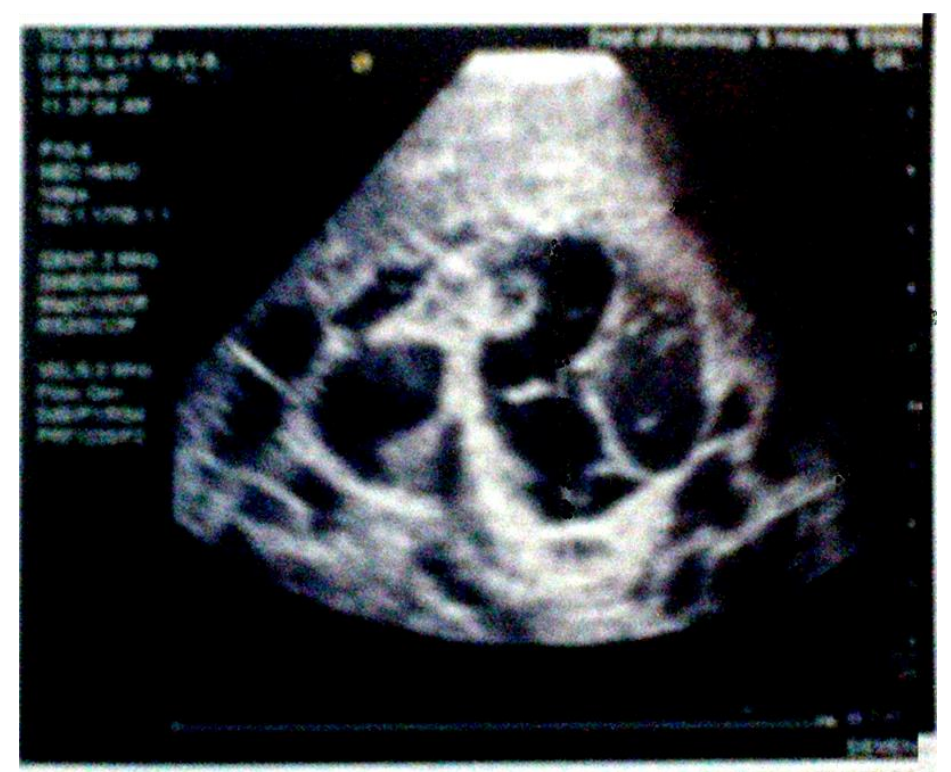

Fig III: Cystic hygroma: Multilocular predominantly cystic mass with septa of variable thickness. 


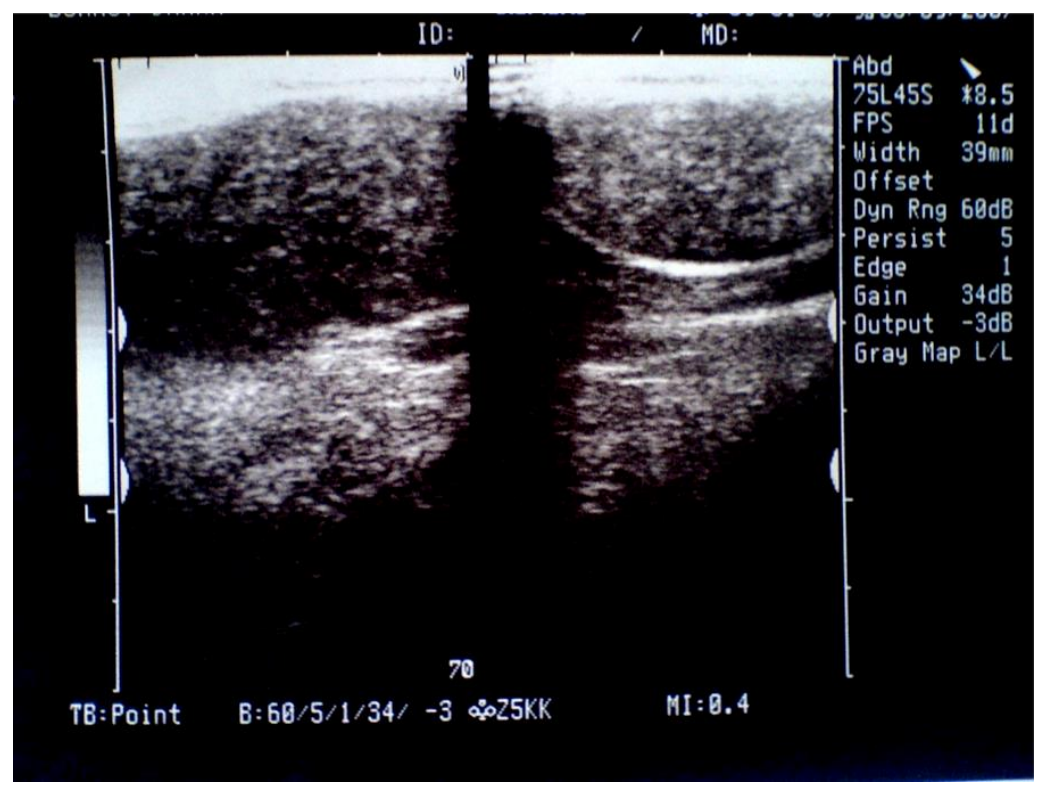

Fig IV: Epidermoid cyst: Midline suprahyoid, sub-mental mass showing moderately thin walled, unilocular cystic lesion having coarse internal echoes without posterior echo enhancement.

\section{Discussion}

Cystic lesions in the cervical region are relatively frequent findings. Differentiation of these disease processes is important for proper management. Clinical history and physical examination are often not enough for definite diagnosis. Ultrasound especially high frequency ultrasound not only confirms the cystic nature of the lesion but also evaluates exact location, size, extent, relation to the surrounding structures and internal characteristic of mass.

Congenital cystic mass are a common malformation in the neck region develop from embryonic rests. The main objective of the present study was to differentiation of them by USG and correlation with histopathology. Clinically suspected 50 patients were studied. The out come of the study were discussed below.

The age of the patient in this series ranged from 1 day to 38 years. The mean age was $14.2 \pm 1.33$ (mean \pm SE) years. The peak incidence was between 11 to 20 years and most of the patients belong to $1^{\text {st }}$ and $2^{\text {nd }}$ decades.

In a study shown that congenital cystic masses in the cervical region usually diagnosed in infancy and childhood. ${ }^{1}$ Most of the lesion present within $2^{\text {nd }}$ decade of life such as $50 \%$ of thyroglossal cyst present before 20 years of age. $5,680 \%$ to $90 \%$ cystic hygroma present in 2nd years old. ${ }^{21,11}$ In the current study $90 \%$ of lesions present within 20 years of age.

In an article among the congenital cystic neck masses $70 \%$ are thyroglossal duct cysts and cystic hygroma $5 \% .{ }^{9}$ In another article Mazharul Alam Siddique, Mahbuba Hossen showing thyroglossal cysts $58.33 \%$, Branchial cyst $19.44 \%$, Lymphangioma $8.33 \%$, haemangioma $8.33 \%$ Dermoid cyst $5.55 \% .{ }^{22}$ In the current study thyroglossal duct cyst $56.3 \%$, bronchial clef cyst $25 \%$, cystic hygroma $12.5 \%$, Hemangioma $3.1 \%$ and epidermoid $3.1 \%$.

In an article on sonography of congenital neck masses in children, 53 patients 
were evaluated. Out of the total population; $58 \%$ of lesions were located at the midline and $42 \%$ in the lateral portions of the neck. ${ }^{23}$ In the current study $59.37 \%$ of lesions were located at the midline and $40.62 \%$ in the lateral portions of the neck.

Histopathology reports of present study revealed $32(64 \%)$ congenital mass and $18(36 \%)$ non-congenital masses. The USG reports provided $37(74 \%)$ congenital and $13(26 \%)$ noncongenital masses.

30 patients were diagnosed as congenital cystic mass by ultrasound and confirmed by histopathology, they were true positive. 7 patients of USG diagnosis of congenital masses not confirmed by histopathology, they were false positive. 11 patients were diagnosed as non-congenital cystic mass by ultrasound confirmed by histopathology, they were true negative. And remaining 2 USG diagnosis not confirmed by histopathology, they were false negative.

Sensitivity of USG to diagnose of congenital cystic neck mass was $93.7 \%$, specificity $64 \%$ and accuracy $74 \%$.

\section{Conclusion}

The results of the present study conclude that USG is a useful modality for the diagnosis of congenital cystic mass in the cervical region. Since the USG diagnosis correlate with histopathological connection is a gold standard on the basis of above findings.

\section{Bibilography}

1. Koeller KK, Alamo L, Adair CF, Smimiotopoulos JF. Congenital cystic masses of the neck: radiologic pathologic correlation. Radiographics 1999; 19:121-146.

2. Ibrahim M, Hammoud K, Maheshwari M, Pandya A. Congenital cystic lesions of the head and neck. Neuroimaging Clin $\mathrm{N}$ Am. 2011;2:621-639, viii.
3. Lev S, Lev MH. Imaging of cystic lesions. Radiol Clin North Am. 2000;38:1013-1027.

4. Al-Dousary S. Current management of thyroglossal-duct remnant. J Otolaryngol. 1997;26:259-265.

5. Harnsberger $\mathrm{H}$. Handbook of head and neck imaging 2nd ed. St Louis, Mo: Mosby-Yearbook, 1995.

6. Telander R, Deane S. Thyroglossal and branchial cleft cysts and sinuses. Surg Clin North Am 1977; 57:779791.

7. Telander $\mathrm{R}$, Filston $\mathrm{H}$. Review of head and neck lesions in infancy and childhood. Surg Clin North Am 1992; 72:1429-1447.

8. Anil T. Ahuja, ann D. King, Walter King and Con Meterweli. Thyroglossal duct cysts: Sonographic Appreance in Adults. Amrican Journal of Neuroradiology 20:579582(4 1999).

9. Bajaj $\mathrm{Y}$, Ifeacho $\mathrm{S}$, Tweedie $\mathrm{D}$, et al. Branchial anomalies in children. Int $\mathrm{J}$ Pediatr Otorhinolaryngol. 2011;75:1020-1023.

10. Harnsberger HR, Mancuso AA, Muraki AS, et al. Branchial cleft anomalies and their mimics: Computed tomographic evaluation. Radiology. 1984;152:739-748.

11. Miller M, Rao V, Tom B. Cystic masses of the head and neck: pitfalls in CT and MR interpretation. AJR 1992; 159:601-607.

12. Smith L, Hamilton JS. Pediatric submental cavernous lymphangioma. Ear Nose Throat J. 2006;85:372-373.

13. Fung K, Poenaru D, Soboleski DA, Kamal IM. Impact of magnetic resonance imaging on the surgical management of cystic hygromas. $\mathrm{J}$ Pediatr Surg. 1998;33:839-841.

14. Som P, Sacher M, Lanzieri C, et al. Parenchymal cysts of the lower neck. Radiology 1985; 157:399-406.

15. Silverman $\mathrm{P}$, Korobkin M, Moore A. CT diagnosis of cystic hygroma of 
the neck. J Comput Assist Tomogr 1983; 7:519-520.

16. Sheath $S$, Nussbaum A, Hutchins G, Sanders R. Cystic hygromas in children: sonographic-pathologic correlation. Radiology 1987; 162:821-824.

17. Foley DS, Fallat ME. Thyroglossal duct and other congenital midline cervical anomalies. Semin Pediatr Surg. 2006;15:70-75.

18. Som P. Cystic lesions of the neck. Postgrad Radiol 1987; 7:211-236.

19. Park Y. Evaluation of neck masses in children. Am Fam Phys 1995; 51:1904-1912.

20. Yassumoto M Shibuya H, Gomi N, Kasuga T. Ultrasonographic apearance of dermoid and epidermoid cysts in the head and neck. J Clin Ultrasound 1991; 19:455-461.

21. Faerber E, Swartz J. Imaging of neck masses in infants and children. Crit Rev Diag Imaging 1991; 31:283-314.

22. Mazharul Alam Siddique, Mahbuba Hossen. Clinical presentation of congenital neck mass in children. Bangladesh $\mathrm{J}$ Otorhinolaryngology 2012; 18(1): 16-22.

23. Sladjana Petrovic, Dragan Petrovic, Zoran Pesic, Predrag Kovacevic. Sonography of congenital neck masses in children. Facta Universitis. Medicine and biology. Vol. 12, No3, 2005, pp.164-169. 